\title{
Roles of heme oxygenase-1 in curcumin-induced growth inhibition in rat smooth muscle cells
}

\author{
Hyun-Ock Pae ${ }^{1,2,5 *}$, Gil-Saeng Jeong ${ }^{1,4 *}$, \\ Sun-Oh Jeong ${ }^{2}$, Hak Sung Kim ${ }^{1,4}$, \\ Soon-Ai Kim ${ }^{1,4}$, Youn-Chul Kim ${ }^{1,4}$, \\ Su-Jin $\mathrm{Yoo}^{3}$, Heung-Doo $\mathrm{Kim}^{6}$ and \\ Hun-Taeg Chung ${ }^{1,2,7}$ \\ ${ }^{1}$ Medicinal Resources Research Institute \\ ${ }^{2}$ Department of Microbiology and Immunology \\ ${ }^{3}$ Department of Emergency \\ Wonkwang University School of Medicine \\ ${ }^{4}$ College of Pharmacy \\ ${ }^{5}$ Professional Graduate School of Oriental Medicine \\ Wonkwang University \\ Iksan 570-749, Korea \\ ${ }^{6}$ Department of Clinical Pathology \\ Sohae College \\ Gunsan 573-717, Korea \\ ${ }^{7}$ Corresponding author: Tel, 82-63-850-6762; \\ Fax, 82-63-851-5066; E-mail, htchung@wonkwang.ac.kr \\ *These authors contributed equally to this work.
}

Accepted 12 March 2007

Abbreviations: ARE, antioxidant response element; HASMCs, human aortic smooth muscle cells; HO-1, heme oxygenase-1; Nrf2, nuclear transcription factor E2-related factor-2; VSMCs, vascular smooth muscle cells

\begin{abstract}
In vascular smooth muscle cells (VSMCs), induction of the heme oxygenase-1 (HO-1) confers vascular protection against cellular proliferation mainly via its up-regulation of the cyclin-dependent kinase inhibitor $\mathrm{P21}{ }^{\mathrm{WAF} 1 / \mathrm{CIP} 1}$ that is involved in negative regulation of cellular proliferation. In the present study, we investigated whether the phytochemical curcumin and its metabolite tetrahydrocurcumin could induce HO-1 expression and growth inhibition in rat VSMCs and, if so, whether their antiproliferative effect could be mediated via HO-1 expression. At non-toxic concentrations, curcumin possessing two Michael-reaction acceptors induced HO-1 expression by activating antioxidant response element (ARE) through translocation of the nuclear trans cription factor E2-related factor-2 (Nrf2) into the nucleus and also inhibited VSMC growth triggered
\end{abstract}

by $5 \%$ FBS in a dose-dependent manner. In contrast, tetrahydrocurcumin lacking Michael-reaction acceptor showed no effect on HO-1 expression, ARE activation and VSMC growth inhibition. The antiproliferative effect of curcumin in VSMCs was accompanied by the increased expression of p21 ${ }^{\text {WAF } 1 / C I P 1}$. Inhibition of VSMC growth and expression of p21 ${ }^{\text {WAF } 1 / C I P 1}$ by curcumin were partially, but not completely, abolished when the cells were coincubated with the $\mathrm{HO}$ inhibitor tin protoporphyrin. In human aortic smooth muscle cells (HASMCs), curcumin also inhibited growth triggered by TNF- $\alpha$ and increased p21 ${ }_{\text {WAF1/CIP1 }}$ expression via HO-1dependent manner. Our findings suggest that curcumin has an ability to induce HO-1 expression, presumably through Nrf2-dependent ARE activation, in rat VSMCs and HASMCs, and provide evidence that the antiproliferative effect of curcumin is considerably linked to its ability to induce HO-1 expression.

Keywords: carbon monoxide; cell proliferation; curcumin; heme oxygenase-1; NF-E2-related factor 2; muscle, smooth, vascular

\section{Introduction}

Vascular smooth muscle cells (VSMCs) comprise the major cellular component of the normal arterial wall and the excessive growth of VSMCs is a key abnormality in the development of atherosclerosis lesions and restenosis after balloon angioplasty (Sata, 2006). Therefore, inhibition of VSMC proliferation represents an important therapeutic strategy for treatment of these diseases. Recently, it has been well established that heme oxygenase-1 (HO-1), the inducible enzyme that uses the pro-oxidant heme as a substrate to produce bilirubin/biliverdin and carbon monoxide (CO), confers vascular protection against abnormal proliferation (Durante, 2003). For example, VSMCs from HO-1-deficient mice display abnormal growth (Yet et al., 2003). Conversely, over-expression of HO-1 by either transfection of the HO-1 gene or exogenous administration of a certain HO-1 inducer reduces excessive VSMC proliferation (Juan et al., 2001). Thus, genetic approaches targeting HO-1 or pharmacological interventions using HO-1 inducers may offer a promising therapeutic modality in treating occlusive vascular disease. 
The rhizome of Curcuma longa (turmeric) has been widely used as a spice and coloring agent in many foods. Consumption of turmeric has been associated with various beneficial effects on human health (Chainani-Wu, 2003). Turmeric has also been used as a traditional remedy for the treatment of inflammation and other diseases (Surh, 2002). Curcumin (chemical structure shown in Figure 1), as a major biologically active compound, is isolated from the turmeric (Surh, 2002). A wide range of biological and pharmacological activities of curcumin have been investigated (Maheshwari et al., 2006). The dietary pigment curcumin is rapidly metabolized during absorption from the intestine, yielding colorless tetrahydrocurcumin (chemical structure shown in Figure 1) (Sugiyama et al., 1996), which has shown the stronger antioxidant activity than curcumin (Huang et al., 1995). Several studies in experimental animals indicated that like curcumin, tetrahydrocurcumin is also effective in cancer prevention (Huang et al., 1995) and protection against inflammation (Ireson et al., 2001) and hepatotoxicity (Pari and Murugan, 2004). Thus, tetrahydrocurcumin was thought to be one of the metabolites with higher physiological and pharmacological activities than curcumin in the intestine.

Recently, it has been reported that curcumin is capable of inhibiting VSMC proliferation (Yang et al., 2006). However, a possible mechanism of antiproliferative action of curcumin is not fully understood. Curcumin can induce $\mathrm{HO}-1$ expression in endothelial cells (Jeong et al., 2006), renal epithelial cells (Balogun et al., 2003), and astrocytes (Scapagnini et al., 2002), and HO-1 expression in these types of cells mediates pharmacological actions of curcumin. In this regard, it is questioned whether curcumin could induce HO-1 expression also in rat VSMCs and, if so, whether inhibition of VSMC proliferation by curcumin could be mediated via its $\mathrm{HO}-1$ expression. It is also questioned whether the curcumin<smiles>COc1cc(/C=C/C(=O)CC(=O)/C=C/c2ccc(O)c(OC)c2)ccc1O</smiles><smiles>COc1cc(CCC(=O)CC(=O)CCc2ccc(O)c(OC)c2)ccc1O</smiles>
Tetrahydrocurcumin

Figure 1. Chemical structures of curcumin and tetrahydrocurcumin. metabolite tetrahydrocurcumin may be also effective in HO-1 expression and growth inhibition in VSMCs.

The nuclear transcription factor E2-related factor 2 (Nrf2) has a highly conserved basic region-leucinezipper structure and belongs to the cap-n-collar family together with Nrf1 and Nrf3. Nrf2 forms heterodimers with the small oncogene family proteins for the selective recognition of the antioxidant responsive element (ARE) on target genes, followed by the regulation of gene expression of phase II detoxifying enzymes including HO-1 (Srisook et al., 2005). From several lines of investigation, it is reported that curcumin stimulates $\mathrm{HO}-1$ gene activity by promoting dissociation of the Nrf2-Keap1 complex, leading to increased Nrf2 binding to the resident HO-1 AREs (Balogun et al., 2003).

In the present study, we demonstrated that curcumin, but not tetrahydrocurcumin, induced HO-1 expression by activating ARE through Nrf2 nuclear translocation and growth inhibition in rat VSMCs. In addition, we provide evidence that the antiproliferative effect of curcumin is mediated considerably through its HO-1 expression not only in rat VSMCs but also in human aortic smooth muscle cells (HASMCs).

\section{Materials and Methods}

\section{Reagents}

Curcumin ( $>95 \%$ pure) was isolated from the rhizomes of turmeric, as described earlier (Jeong et al., 2006). Tetrahydrocurcumin ( $>95 \%$ pure) was prepared from curcumin by hydrogenating the two double bonds conjugated to the $\beta$-diketone (Figure 1), as described previously (Uehara et al., 1987). DMEM and FBS were obtained from Gibco/Invitrogen (Carlsbad, CA). Bilirubin, biliverdin, ferrous citrate, HEPES, 4,6Diamidino-2-phenylindole (DAPI), hemin, trypsin, and monoclonal antibody against smooth muscle $\alpha$-actin were purchased from the Sigma- Aldrich (St. Louis, $\mathrm{MO})$. Antibodies for HO-1, Nrf2, p2 $7^{\mathrm{KIP} 1}$ and $\mathrm{p} 21^{\mathrm{WAF} / \mathrm{CIP} 1}$ were purchased from Santa Cruz Biotechnology (Santa Cruz, CA). $\left[{ }^{3} \mathrm{H}\right]$ thymidine was purchased from Dupont/New England Nuclear (Boston, MA). Cupper protoporphyrin (CuPP) and tin protoporphyrin (SnPP) were from Porphyrin Products (Logan, UT). Recombinant TNF- $\alpha$ was purchased from Sigma-Aldrich. All other chemicals were of the highest purity commercially available.

\section{Rat VSMC isolation and culture}

Rat VSMCs were isolated by enzymatic dispersion, as previously described (Kim et al., 2002). Cells were cultured in DMEM supplemented with $10 \%$ FBS, $100 \mathrm{U} / \mathrm{ml}$ penicillin, $100 \mu \mathrm{g} / \mathrm{ml}$ streptomycin, 8 
$\mathrm{mM}$ HEPES and $2 \mathrm{mM}$ L-glutamine at $37^{\circ} \mathrm{C}$ in a humidified $5 \% \mathrm{CO}_{2}$ incubator. The purity of VSMCs cultures was confirmed by the immunocytochemical localization of $\alpha$-smooth muscle actin. VSMCs from between passages 3 and 6 were used in this experiment. This study was performed via a protocol approved by the Institutional Animal Care and Use Committee of Wonkwang University in accordance with the Guide for the Care and Use of Laboratory Animals.

Human aortic smooth muscle cells (HASMC) were purchased from Bio-Whittaker (San Diego, CA) and cultured in smooth muscle cell growth medium containing $10 \%$ FBS, $2 \mathrm{ng} / \mathrm{ml}$ of human basic fibroblast growth factor, $0.5 \mathrm{ng} / \mathrm{ml}$ of human EGF, 50 $\mu \mathrm{g} / \mathrm{ml}$ of gentamycin, $50 \mu \mathrm{l} / \mathrm{ml}$ of amphotericin-B, and $5 \mu \mathrm{g} / \mathrm{ml}$ of bovine insulin.

\section{Plasmids, transfections and luciferase assays}

To construct ARE-Luciferase vector, tandem repeats of double-stranded oligonucleotides spanning the Nrf2 binding site 5'-TGACTCAGCA-3' (Lee et al., 2006) were introduced into the restriction sites of the pGL2 promoter plasmid (Madison, WI). The human p21 $1^{\text {WAF1/CIP1 }}$ promoter construct was a gift from Dr. Bert Vogelstein (el-Deiry et al., 1993). All transfection experiments were performed using lipofectamine reagent (Invitrogen, Carlsbad, CA) according to the manufacturer's instructions. For luciferase assays, the cell lysate was first mixed with the luciferase substrate solution (Promega), and luciferase activity was measured using a luminometer. For each experiment, luciferase activity was determined in triplicate and normalized for each sample using $\beta$ galactosidase activity.

\section{Cell proliferation and $\left[{ }^{3} \mathrm{H}\right]$ thymidine incorporation assays}

For all experiments, cells were made quiescent by serum-free medium for $48 \mathrm{~h}$ before adding mitogenic agents or test compounds to the medium. VSMCs, grown to near confluence in 12-well tissue culture plates, were made quiescent and treated with curcumin, as indicated. Cells were stimulated with $5 \%$ FBS (for rat VSMCs) or $100 \mathrm{ng} / \mathrm{ml} \mathrm{TNF-} \alpha$ (for HASMCs), trypsinized with trypsin-EDTA, and counted using a hemocytometer. To assess the count of viable cells, an equal volume of trypan blue dye solution $(0.1 \% \mathrm{w} / \mathrm{v})$ was added briefly to stain a portion of the cells.

For $\left[{ }^{3} \mathrm{H}\right]$ thymidine incorporation experiments, cells were seeded in 24-well culture plates under the above-mentioned conditions, and $2 \mu \mathrm{Ci} / \mathrm{ml}$ of $\left[{ }^{3} \mathrm{H}\right]-$ thymidine was added to medium for $4 \mathrm{~h}$. Reactions were terminated by aspirating medium and washing cultures with PBS containing 10\% trichloroacetic acid and ethanol/ether $(1: 1, v / v)$. The acid-insoluble $\left[{ }^{3} \mathrm{H}\right]$ thymidine was extracted into $250 \mu \mathrm{l}$ of $0.5 \mathrm{M}$ $\mathrm{NaOH} /$ well, and this solution was then mixed with 3 $\mathrm{ml}$ of scintillation cocktail (Ultimagold, Packard Bioscience, CT), and quantified using a liquid scintillation counter (LS3801, Beckman, Düsseldorf, Germany). Protein contents were determined in $50 \mu$ aliquots of residual solutions using BCA Protein Assay Reagent Kits (Pierce Biotechnology, Rockford, IL).

\section{Western blotting analysis for protein expression} After treatment, cells $\left(3 \times 10^{6}\right.$ cells $/ 3 \mathrm{ml}$ in $60 \mathrm{~mm}$ dish) were collected and washed with PBS. After centrifugation, cell lysis was carried out at $4^{\circ} \mathrm{C}$ by vigorous shaking for $15 \mathrm{~min}$ in RIPA buffer [150 mM $\mathrm{NaCl}, 1 \% \mathrm{NP}-40,0.5 \%$ sodium deoxycholate, $0.1 \%$ SDS, $50 \mathrm{mM}$ Tris- $\mathrm{HCl}(\mathrm{pH} 7.4), 50 \mathrm{mM}$ glycerophosphate, $20 \mathrm{mM} \mathrm{NaF}, 20 \mathrm{mM}$ EGTA, $1 \mathrm{mM}$ DTT, 1 $\mathrm{mM} \mathrm{Na}_{3} \mathrm{VO}_{4}$ and protease inhibitors]. After centrifugation at $14,800 \times g$ for $15 \mathrm{~min}$, the supernatant was separated and stored at $-70^{\circ} \mathrm{C}$ until use. The protein concentration was determined by using the BCA Protein Assay Reagent Kit (Pierce Biotechnology). After addition of sample loading buffer, protein samples were electrophoresed on a $12.5 \%$ SDS-polyacrylamide gel. Proteins were transferred to polyvinylidene difluoride blots at $300 \mathrm{~mA}$ for $6 \mathrm{~h}$. The blots were blocked for $1 \mathrm{~h}$ at room temperature in fresh blocking buffer $(0.1 \%$ Tween 20 in Trisbuffered saline, $\mathrm{pH} 7.4$, containing $5 \%$ non-fat dried milk). Dilutions $(1: 1,000)$ of primary antibodies were made in PBS with $3 \%$ non-fat dried milk. Following three washes with PBST (PBS and $0.1 \%$ Tween 20), the blots were incubated with HRP-conjugated secondary antibodies (Santa Cruz Biotechnology) in PBS with $3 \%$ non-fat dried milk for $1 \mathrm{~h}$ at room temperature. The blots were washed again three times in PBST buffer, and transferred proteins were incubated with ECL substrate solution (Amersham Pharmacia Biotech, Piscataway, NJ) for $1 \mathrm{~min}$ according to the manufacturer's instructions followed by visualization with $\mathrm{X}$-ray film.

\section{HO activity assay}

Cells $\left(2.5 \times 10^{6}\right.$ cells $)$ were treated with vehicle, hemin (positive control) or curcumin for $6 \mathrm{~h}$. Cell pellets were re-suspended in magnesium supplemented potassium phosphate solution [MgCl-PBS; $100 \mathrm{mM}$ potassium phosphate and $2 \mathrm{mM}$ magnesium chloride; $\mathrm{pH}$ 7.4] and subjected to three freeze-thaw cycles for release of cytoplasmic $\mathrm{HO}-1$ proteins. HO-1 enzymatic assay used a reaction mixture containing $100 \mathrm{mM}$ PBS, $2 \mathrm{mM} \mathrm{MgCl}$, $3 \mathrm{mg}$ of rat liver cytosol, $0.8 \mathrm{mM} \mathrm{NADPH}, 2 \mathrm{mM}$ glucose-6phosphate (Sigma), $0.2 \cup$ of glucose-6-phosphate 
dehydrogenase and $20 \mu \mathrm{M}$ enzyme substrate hemin (Porphyrin Products) plus $400 \mu \mathrm{l}$ of sample. The reaction was made up to a final volume of $1 \mathrm{ml}$ for each sample and was incubated at $37^{\circ} \mathrm{C}$ for $1 \mathrm{~h}$ in the dark. Chloroform was added to terminate the reaction, and bilirubin was extracted following centrifugation, and measured by spectrophotometry reading the difference in absorbance between 464 and $530 \mathrm{~nm}\left(\varepsilon=40 \mathrm{mM}^{-1} \mathrm{~cm}^{-1}\right)$. The protein concentration in each sample was determined with the BCA Protein Assay Reagent Kit (Pierce Biotechnology), and the HO-1 activities were expressed in picomoles of bilirubin formed per milligram of protein per hour.

\section{Nrf2 Localization and immunofluorescence}

Quiescent VSMCs were treated with curcumin for 6 $\mathrm{h}$ and then cultured with DMEM containing 5\% FBS for $24 \mathrm{~h}$. The cells were then washed in PBS, fixed with $4 \%$ paraformaldehyde for $20 \mathrm{~min}$ at room temperature, and washed again in PBS. To visualize the nuclei, cells were then treated with $1 \mu \mathrm{g} / \mathrm{ml}$ of DAPI for $30 \mathrm{~min}$, washed again with PBS for $5 \mathrm{~min}$, and treated with $50 \mu \mathrm{l}$ of VectaShield (Vector Laboratories, Burlingame, CA). For localization of Nrf2, rat VSMCs were grown on Lab-Tek II chamber slides and treated as described in figure legends. The cells were treated with $20 \mu \mathrm{M}$ curcumin for $1 \mathrm{~h}$. Cells were then fixed in formalin and permeabilized with cold acetone. The cells were probed with Nrf2 antibody followed by FITC-labeled secondary antibody (Santa Cruz Biotechnology). Stained cells were visualized and photographed using a Zeiss fluorescence microscope (Provis AX70; Olympus Optical Co., Tokyo, Japan). Apoptotic cells were morphologically defined by nuclear shrinkage and by chromatin condensation or fragmentation.

\section{Results}

Effects of curcumin and tetrahydrocurcumin on HO-1 expression and heme oxygenase activity in rat VSMCs

Curcumin has previously been reported to increase
A

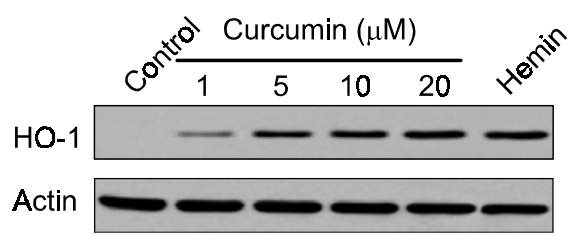

B

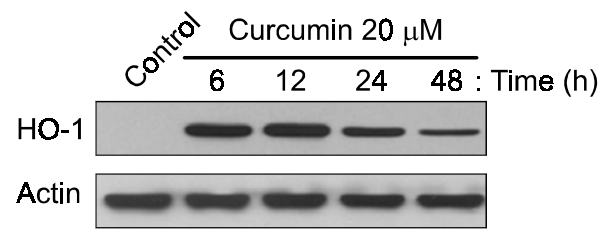

C

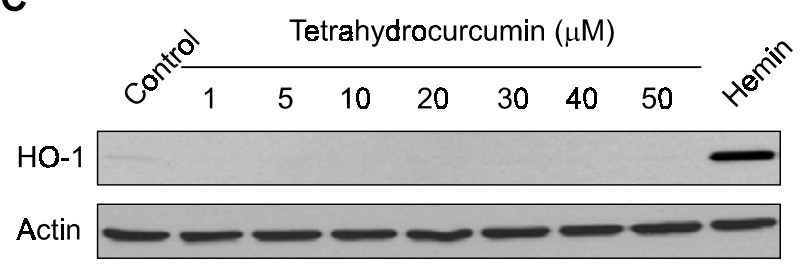

D

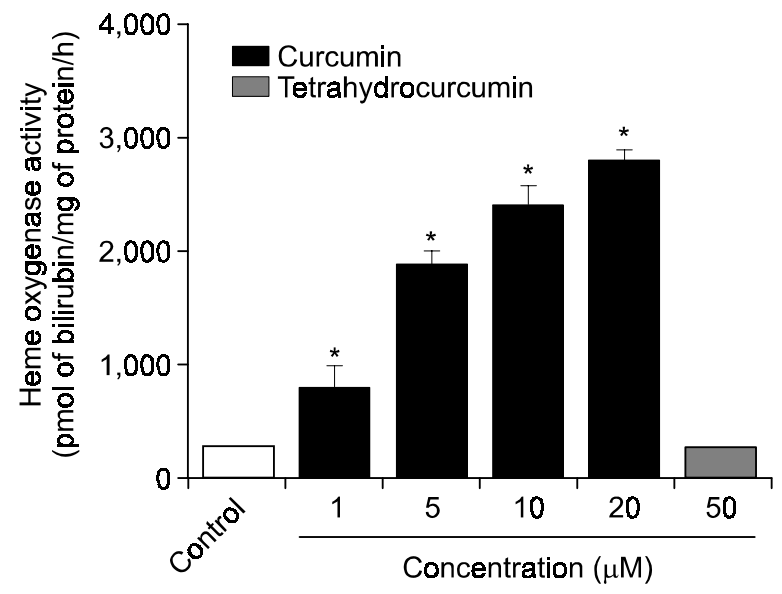

Figure 2 Effects of curcumin and tetrahydrocurcumin on HO-1 expression and $\mathrm{HO}$ activity in rat VSMCs. Quiescent cells were incubated for $6 \mathrm{~h}$ with indicated concentrations of curcumin ( $A$ and $D$ ) or tetrahydrocurcumin ( $C$ and $D)$. (B) Quiescent cells were incubated for indicated periods with $20 \mu M$ of curcumin. Expression of HO-1 (A, B and C) was determined by Western blot analysis described under Materials and Methods, and representative blots of 3 independent experiments are shown. Heme oxygenase activity (D) was determined via bilirubin formation as described under Materials and Methods. Data shown are mean \pm SEM of 6 independent observations in separate cell culture wells. ${ }^{*} P<0.05$, treatment vs. control, one-way ANOVA and Bonferroni's multiple comparison test. 
HO-1 expression (Scapagnini et al., 2002; Balogun et al., 2003; Jeong et al., 2006). However, this effect has not been reported in rat VSMCs to date. In rat VSMCs, curcumin dose-dependently increased HO-1 expression (Figure 2A) and heme oxygenase activity (Figure 2D). A marked increase in $\mathrm{HO}-1$ levels was first observed at $6 \mathrm{~h}$ after treatment, with subsequent decrease thereafter (Figure 2B). Despite displaying a similar basic chemical structure (see chemical structure shown in Figure 1), the metabolite tetrahydrocurcumin did not induce $\mathrm{HO}-1$ expression even at higher concentrations (Figure $2 \mathrm{C}$ ). It should be noted that $\mathrm{HO}-1$ expression and heme oxygenase activity were analyzed in non-cytotoxic concentrations of each tested compound. At $40 \mu \mathrm{M}$, curcumin, but not tetrahydrocurcumin, induced apoptosis of VSMCs (see Figure 4C), and curcumin concentrations ranging 1-20 $\mu \mathrm{M}$ were, therefore, selected for further studies.

\section{Effects of curcumin and tetrahydrocurcumin on Nrf2 nuclear localization and ARE activation in rat VSMCs}

Exposure of cells to the naturally occurring antioxidants possessing Michael-reaction acceptor disrupts the Keap1-Nrf2 complex, allowing Nrf2 to trans- locate into the nucleus, where it binds to ARE and activates transcription (Balogun et al., 2003). Fluorescence microscopy of rat VSMCs revealed the nuclear localization of Nrf2 in response to curcumin possessing two Michael-reaction acceptors (Figure $3 \mathrm{~A})$. Western blot analysis of the nuclear fractions of curcumin-treated cells showed a gradual increase in Nrf2 levels with time, while they declined concomitantly in the cytoplasm (Figure 3B).

Rat VSMCs transiently transfected with AREluciferase plasmid were exposed to either curcumin or tetrahydrocurcumin, and changes in luciferase activity were used as a measure of ARE activation. Figure $3 \mathrm{C}$ shows that curcumin dose-dependently increased ARE-driven luciferase activity; this ARE activation was strongly associated with an increase in heme oxygenase activity (Figure 2D). Unlike curcumin, tetrahydrocurcumin lacking Michael-reaction acceptor had no significant effect on ARE activation (Figure 3C).

\section{Effects of curcumin and tetrahydrocurcumin on proliferation and $\mathrm{p} 21^{\mathrm{WAF} 1 / \mathrm{CIP} 1}$ expression in rat VSMCs} It has been reported that curcumin has an ability to inhibit VSMC proliferation (Yang et al., 2006). We
A

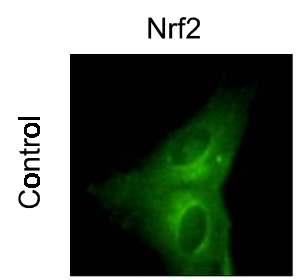

Nucleus
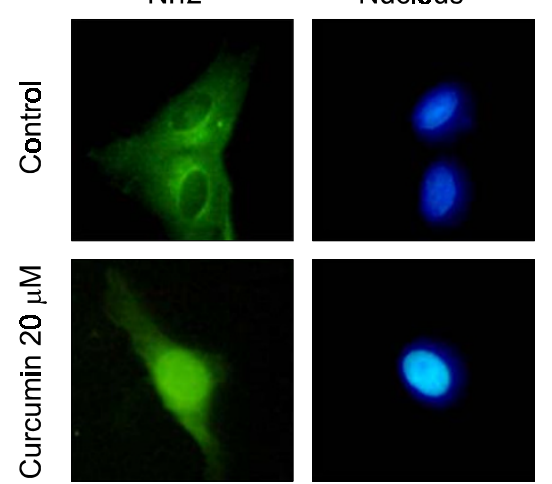

$\mathbf{B}$

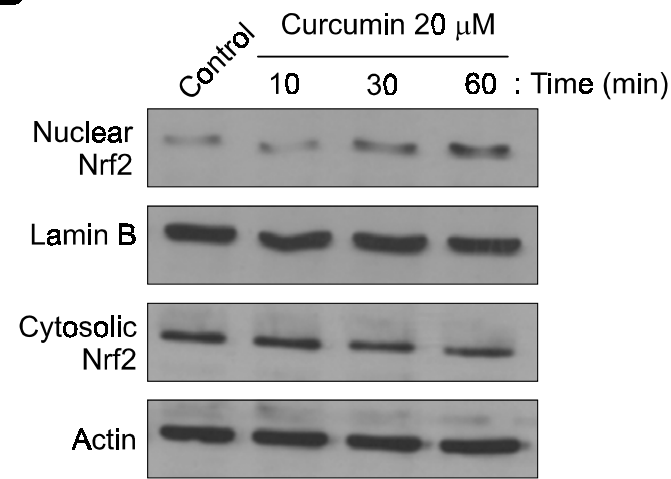

C

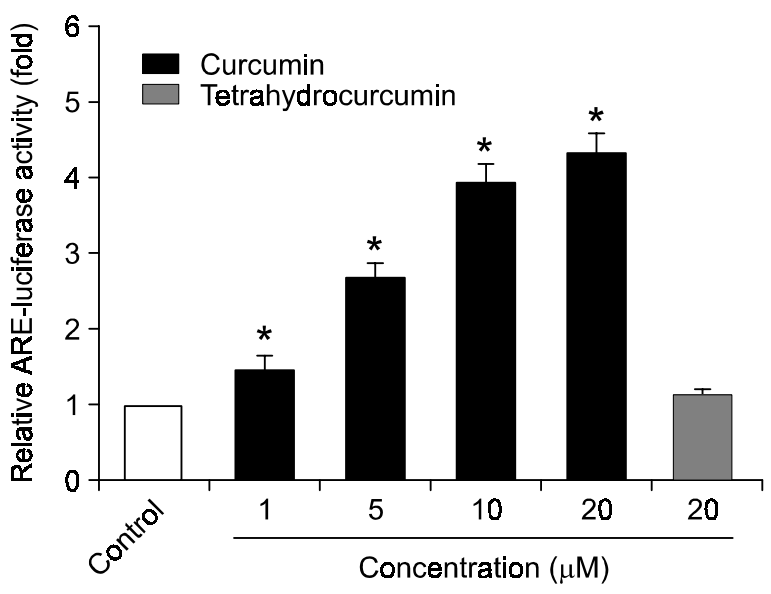

Figure 3 Effects of curcumin and tetrahydrocurcumin on Nrf2 nuclear translocation and ARE activation in rat VSMCs. Quiescent cells were incubated for $1 \mathrm{~h}(\mathrm{~A})$ or indicated periods $(\mathrm{B})$ with $20 \mu \mathrm{M}$ of curcumin. Nrf2 protein was detected by immunofluorescence assay $(A)$ and Western blot analysis (B) as described in Materials and methods, and representative pictures or blots of 3 independent experiments are shown. (C) Quiescent cells transiently transfected with ARE-luciferase or control vector were incubated for $1 \mathrm{~h}$ with indicated concentrations of curcumin or $20 \mu \mathrm{M}$ of tetrahydrocurcumin. Cell lysates were assayed for luciferase activity as the fold induction by normalizing the transfection efficiency and dividing values of each experiment relative to the control. ${ }^{*} P<0.05$, treatment vs. control, one-way ANOVA and Bonferroni's multiple comparison test. 
A

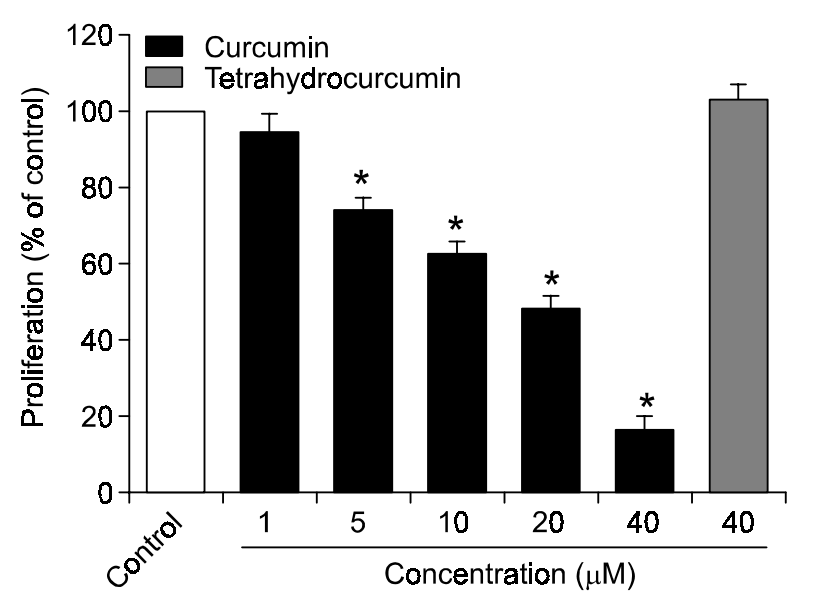

B

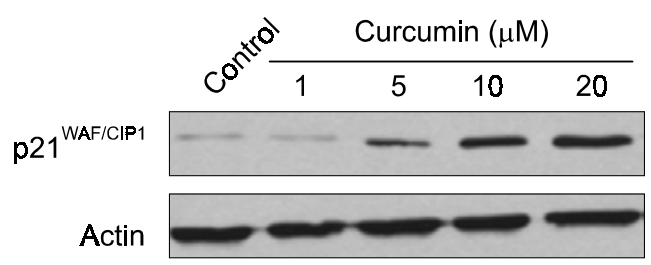

C

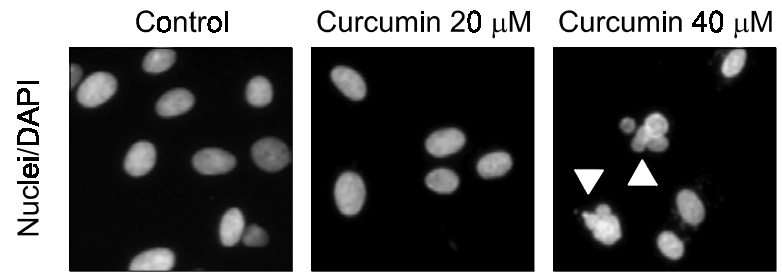

Figure 4 Effects of curcumin and tetrahydrocurcumin on cellular proliferation, p21 WAF/CIP1 expression and apoptosis in rat VSMCs. (A) Quiescent cells were treated for $6 \mathrm{~h}$ with indicated concentrations of curcumin or $40 \mu \mathrm{M}$ of tetrahydrocurcumin and then stimulated for $24 \mathrm{~h}$ with $5 \%$ FBS. The cells were labelled with $\left[{ }^{3} \mathrm{H}\right]$-thymidine for $2 \mathrm{~h}$ at the end of the incubation. Cellular proliferation was assessed by measuring $\left[^{3} \mathrm{H}\right]$ thymidine incorporation as described under Materials and Methods. Data shown are mean \pm SEM of 6 independent observations in separate cell culture wells. ${ }^{*} P<0.05$, treatment vs. control, one-way ANOVA and Bonferroni's multiple comparison test. (B) Quiescent cells were incubated for $12 \mathrm{~h}$ with indicated concentrations of curcumin. Expression of p21 ${ }^{\text {WAFICIP1 }}$ was determined by Western blot analysis described under Materials and Methods, and representative blots of 3 independent experiments are shown. (C) Quiescent cells were incubated for $6 \mathrm{~h}$ with indicated concentrations of curcumin and then stimulated for $24 \mathrm{~h}$ with 5\% FBS. Apoptotic nuclei ( ) were analyzed under fluorescence microscope after DAPI staining as described under Materials and Methods, and representative pictures of 3 independent experiments are shown.

thus examined whether tetrahydrocurcumin might also inhibit VSMC proliferation. Surprisingly, tetrahydrocurcumin was not effective in inhibition of VSMC proliferation (Figure 4A). As expected, curcumin inhibited cellular proliferation triggered by $5 \%$ serum in a dose-dependent manner (Figure 4A). The antiproliferative effect of curcumin in VSMCs was accompanied by the increased expression of the cyclindependent kinase inhibitor p2 ${ }^{\mathrm{WAF} 1 / \mathrm{CIP} 1}$ (Figure 4B). It should be noted that curcumin at $40 \mu \mathrm{M}$ caused apoptosis of VSMCs, which was analyzed by morphological examination of apoptotic nuclei stained with DAPI (Figure 4C) and could explain why cellular proliferation was abnormally dropped at this concentration (Figure 4A).

\section{Roles of HO-1 in curcumin-mediated inhibition of proliferation in rat VSMCs}

Because HO-1 expression in VSMCs is antiproliferative (Durante, 2003), we tested whether curcumin-induced HO-1 expression could facilitate its antiproliferative effect. VSMCs were initially pretreated with curcumin at $20 \mu \mathrm{M}$ for $6 \mathrm{~h}$ in the absence or presence of SnPP, an inhibitor of heme oxygenase activity. The cells were then stimulated with 5\% serum for $48 \mathrm{~h}$ followed by an assessment of cell proliferation. As shown in Figure 5A, SnPP partially reversed the antiproliferative effect of curcumin. In addition, inhibition of VSMC proliferation was also observed when the cells were pre-incubated with hemin, a HO-1 inducer (Figure 5A). CuPP without $\mathrm{HO}-1$-inducing potency was used as a hemin control.

The antiproliferative effects of curcumin and HO-1 are mainly due to their up-regulation of the cyclindependent kinase inhibitor P2 $1^{\text {WAF1/CIP1 } 1}$ that is involved in negative regulation of cellular proliferation (Durante, 2003; Notoya et al., 2006). We thus investigated whether $\mathrm{HO}-1$ expression could be necessary for the $\mathrm{p} 21^{\text {WAF } 1 / \mathrm{CIP} 1}$ up-regulation by curcumin. Treatment of VSMCs with curcumin increased the levels of $\mathrm{p} 21^{\mathrm{WAF} / \mathrm{CIP} 1}$ expression, which was partially abolished by SnPP treatment (Figure 5B). Moreover, p21 $1^{\text {WAF } 1 / \text { CIP } 1}$ expression was also observed when the cells were incubated with hemin (Figure 5B). Unlike their effects on $\mathrm{p} 21^{\text {WAF } 1 / C \mathrm{PI} 1}$ expression, curcumin and hemin had no effect on the expression of $\mathrm{p} 27^{\mathrm{KIP} 1}$ that is another cyclindependent kinase inhibitor. It should be noted that tetrahydrocurcumin showed no significant effect on both $\mathrm{p} 21^{\mathrm{WAF} / / \mathrm{CIP} 1}$ and $\mathrm{p} 27^{\mathrm{KIP} 1}$ expressions (data not shown). Our results suggest that, by activating p2 $1^{\text {WAF } 1 / C I P 1}$ expression, HO-1 expression is necessary for the antiproliferative effects of curcumin in rat VSMCs. 
A

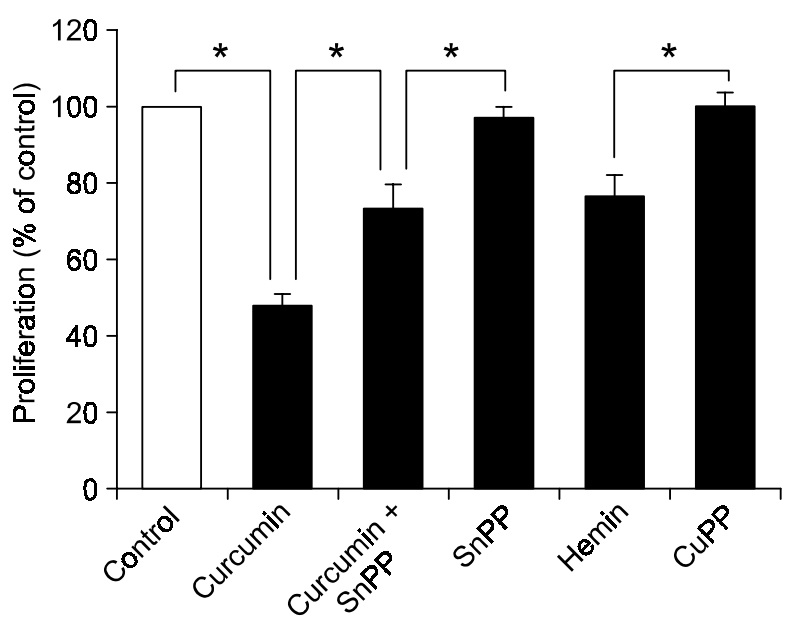

B

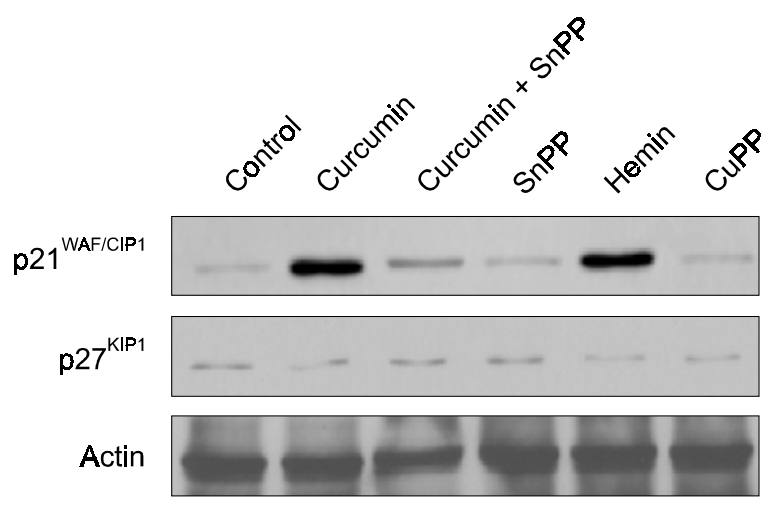

Figure 5 Roles of curcumin-induced $\mathrm{HO}-1$ in cellular proliferation and p21 WAF/CIP1 $e x p r e s s i o n$ in rat VSMCs. (A) Quiescent cells were treated for 6 h with $20 \mu \mathrm{M}$ of curcumin, curcumin plus $20 \mu \mathrm{M}$ of SnPP, $20 \mu \mathrm{M}$ of hemin, or $20 \mu \mathrm{M}$ of CuPP and then stimulated for $24 \mathrm{~h}$ with $5 \%$ FBS. The cells were labelled with $\left[{ }^{3} \mathrm{H}\right.$ ]thymidine for $2 \mathrm{~h}$ at the end of the incubation. Cellular proliferation was assessed by measuring [ $\left.{ }^{3} \mathrm{H}\right]$ thymidine incorporation as described under Materials and Methods. Data shown are mean \pm SEM of 6 independent observations in separate cell culture wells. ${ }^{*} P<0.05$, one-way ANOVA and Bonferroni's multiple comparison test. (B) Quiescent cells were incubated for $12 \mathrm{~h}$, as indicated in panel A. Expression of p21 ${ }^{\text {WAFICIP1 }}$ was determined by Western blot analysis described under Materials and Methods, and representative blots of 3 independent experiments are shown.

\section{Effects of curcumin on HO-1 expression, TNF- $\alpha$-induced proliferation, and P21 WAF1/CIP1 expression in HASMCs}

HASMCs were exposed to increasing concentrations of curcumin using the same protocol as for rat VSMCs. HO-1 expression was significantly detectable at $10 \mu \mathrm{M}$ and $20 \mu \mathrm{M}$ of curcumin, but not at $20 \mu \mathrm{M}$ of tetrahydrocurcumin (Figure 6A). A significant increase in $\mathrm{HO}-1$ activity occurred at $20 \mu \mathrm{M}$ of curcumin (data not shown). In accordance with the results obtained in rat VSMCs, curcumin inhibited cellular proliferation triggered by TNF- $\alpha$ (Figure 6B). This effect was abolished in the presence of SnPP (Figure 6B). In addition, curcumin increased the levels of $\mathrm{p} 21^{\mathrm{WAF} 1 / \mathrm{CIP} 1}$ expression in HASMCs (Figure $6 \mathrm{C})$, as observed in the case of rat VSMCs. Moreover, p21 $1^{\text {WAF1/CIP1 }}$ promoter activity was also increased as the result of curcumin treatment, which was also abolished in the presence of SnPP (Figure $6 \mathrm{D})$. These results show that curcumin-mediated HO-1 expression and antiproliferation are not restricted to rat VSMCs but occur also in HASMCs.

\section{Discussion}

Curcumin derived from turmeric has been shown to suppress proliferation (Notoya et al., 2006; Yang et al., 2006) and induce apoptosis (Chen and Huang,
1998) in a wide variety of cells. It also downregulates the transcription factors, NF- $\mathrm{KB}$ (Dorai and Aggarwal, 2004) and AP-1 (Park et al., 1999). Thereby, this phytochemical displays antioxidant and anti-inflammatory properties and found to suppress tumor initiation, promotion, and metastasis (Dorai and Aggarwal, 2004). Recently, curcumin has been reported to induce the expression of cytoprotective $\mathrm{HO}-1$ in endothelial cells (Jeong et al., 2006), renal epithelial cells (Balogun et al., 2003), and astrocytes (Scapagnini et al., 2002). To our best knowledge, there is so far no available information as to whether curcumin could also induce $\mathrm{HO}-1$ expression in rat VSMCs. In the present study, we found that curcumin induced $\mathrm{HO}-1$ expression and $\mathrm{HO}$ activity in a dose-dependent manner (Figure 2). In contrast, the curcumin metabolite tetrahydrocurcumin lacking Michael-reaction acceptor (chemical structure shown in Figure 1) did not induce $\mathrm{HO}-1$ expression even at higher concentrations. This indicates that two Michael-reaction acceptors ( $\alpha, \beta$-unsaturated carbonyl group) in curcumin molecule may play a pivotal role in $\mathrm{HO}-1$ expression in rat VSMCs. It is interesting to note that curcumin was also effective in inhibition of VSMC proliferation, but its metabolite was not (Figure 3 ). Thus, the effects of curcumin on both $\mathrm{HO}-1$ expression and growth inhibition were determined by the same structural feature. It, therefore, appears that the structural feature of curcumin that is essential for its effect on $\mathrm{HO}-1$ expression is also the 
A

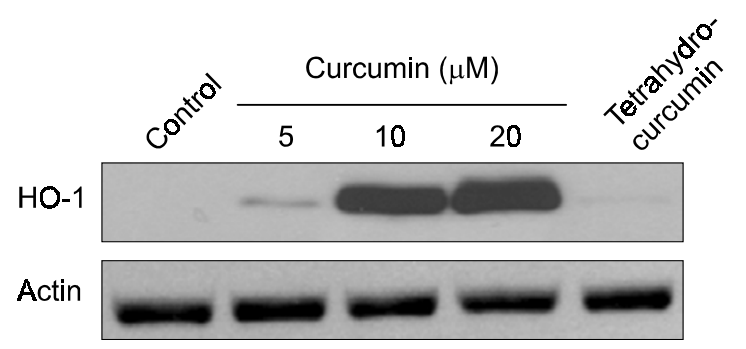

B

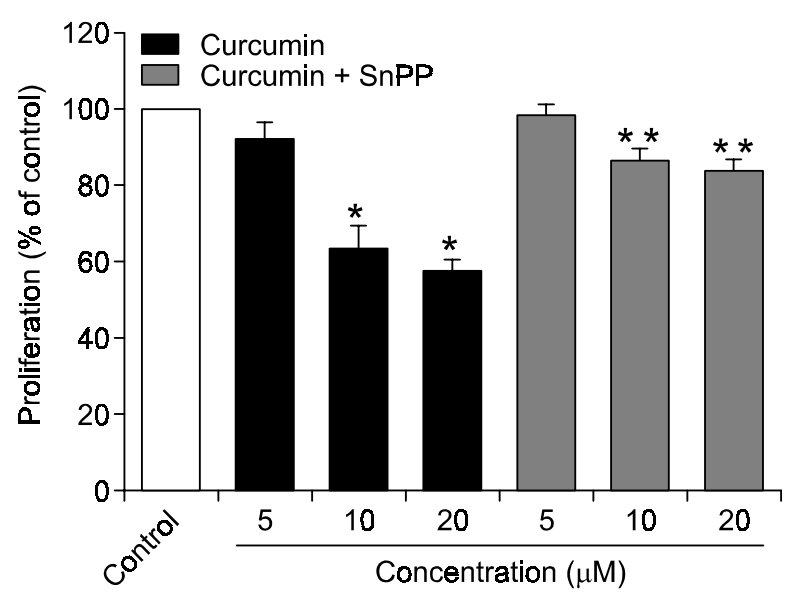

C

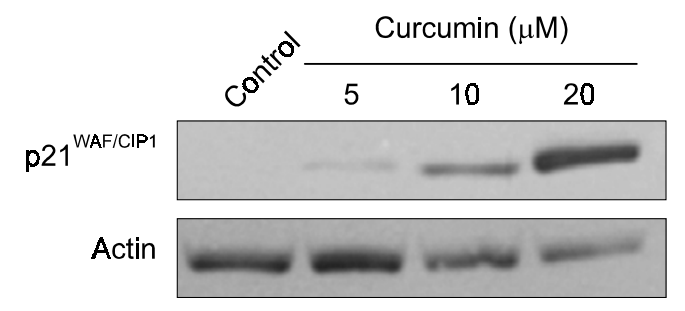

D

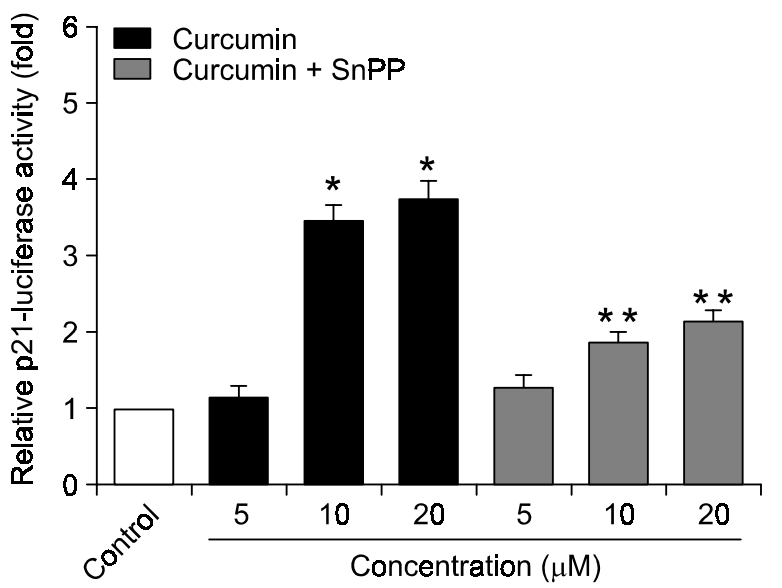

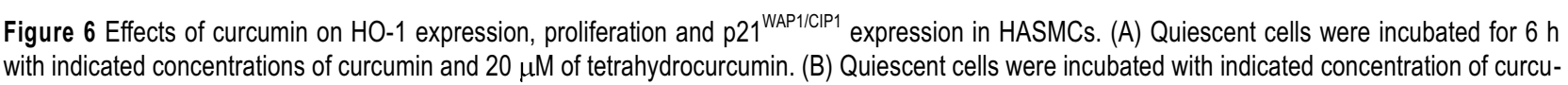
min in the presence or absence of $20 \mu \mathrm{M}$ of SnPP and then stimulated for $24 \mathrm{~h}$ with $100 \mathrm{ng} / \mathrm{ml}$ of TNF- $\alpha$. (C) Quiescent cells were incubated for $12 \mathrm{~h}$ with indicated concentrations of curcumin. (D) Quiescent cells transiently transfected with p21 ${ }^{\text {WAF } 1 / C l P 1}$-luciferase or control vector were incubated for $12 \mathrm{~h}$ with indicated concentrations of curcumin. Expressions of HO-1 (A) and p2 $1^{\text {WAF1/CIP1 }}$ (C) were determined by Western blot analysis described under Materials and Methods, and representative blots of 3 independent experiments are shown. Cellular proliferation (B) was assessed by measuring $[3 H]$ thymidine incorporation as described under Materials and Methods. Data shown are mean \pm SEM of 6 independent observations in separate cell culture wells. ${ }^{*} P<0.05$ with respect to control group and ${ }^{* *} P<0.05$ with respect to the group treated with curcumin at each concentration, one-way ANOVA and Bonferroni's multiple comparison test.

one that is important for its antiproliferative activity. This raises an important question of whether the antiproliferative action of curcumin could be mediated via its HO-1 expression. To test this, we employed the $\mathrm{HO}$ inhibitor SnPP to block HO activity resulted from curcumin-mediated HO-1 expression. Our results showed that inhibition of VSMC proliferation by curcumin was partially, but not completely, reversed in the presence of SnPP (Figure 5). Moreover, the HO-1 inducer hemin significantly inhibited VSMC proliferation (Figure 5). Our findings, therefore, suggest that $\mathrm{HO}-1$ expression may contribute, to a certain extent, to the antiproliferative effect of curcumin, and are consistent with the recent findings that HO-1 expression inhibits VSMC proliferation (Juan et al., 2001).

It is presently unclear how curcumin can induce HO-1 expression in rat VSMCs. The nuclear factor
Nrf2 has recently emerged as a key player in the activation of ARE-mediated gene expression. Nrf2 resides in the cytosol, bound to an inhibitor Keap-1. Upon cell stimulation, Nrf2 is released from Keap-1 and enters the nucleus where it binds to the ARE in the promoters of target genes (Srisook et al., 2005). $\mathrm{HO}-1$ and several other antioxidant genes contain ARE or ARE-like sequences in their promoters (Srisook et al., 2005). It has been reported that curcumin disrupts the Nrf2-Keap1 complex, leading to increased Nrf2 binding to ARE (Banning et al., 2005). In porcine renal epithelial cells, curcumin stimulated nuclear translocation of Nrf2 by inactivating the Nrf2-Keap1 complex, which was associated with a significant increase in the activity and expression of HO-1 (Balogun et al., 2003). In another study, curcumin increased the nuclear translocation of Nrf2, ARE/DNA binding activity (Andreadi et al., 
2006). It is notable that curcumin and other HO-1inducing compounds possess an $\alpha, \beta$-unsaturated carbonyl moiety, and can, therefore, act as Michaelreaction acceptors that are able to modify cysteine thiols present in Keap1 (Surh et al., 2005). Based on our findings that tetrahydrocurcumin lacking Michaelreaction acceptors was not able to induce $\mathrm{HO}-1$ expression (Figure 2) and ARE activation (Figure 3), and curcumin possessing two Michael-reaction acceptors induced HO-1 expression, Nrf2 nuclear translocation and ARE activation in rat VSMCs (Figure 3), it is tempting to speculate that $\mathrm{HO}-1$ expression by curcumin might occur via Nrf2-dependent ARE activation in rat VSMCs.

The molecular basis of the antiproliferative action of $\mathrm{HO}-1$ in rat VSMCs remains to be fully elucidated, but the product of heme degradation, such as $\mathrm{CO}$, seems to be responsible for the antiproliferative effects of HO-1. CO interacts with various components of the cell cycle machinery. The exogenous treatment with this gaseous molecule arrests VSMC in the $G_{1} / S$ transition phase of the cell cycle (Duckers et al., 2001). The inhibition of cell cycle progression by $\mathrm{CO}$ is accompanied with a marked decrease in the phosphorylation of retinoblastoma, a critical event required for S-phase entry and DNA synthesis (Peyton et al., 2002). CO also selectively suppresses the expression of cyclin $A$, while having no effect on the expression of cyclin D1 and $E$ (Peyton et al., 2002). In addition, inhibition of cyclin A expression by $\mathrm{CO}$ results in inhibition of both cyclin A-associated kinase activity and cyclindependent kinase-2 (cdk-2) activity, independent of any changes in the level of cdk-2 protein (Peyton et al., 2002). Because cdk2 is a key regulator of both G1 and S phase cell progression (Braun-Dullaeus et al., 1998), the ability of CO to block cdk2 activity may provide a potent mechanism by which $\mathrm{CO}$ can inhibit VSMC proliferation. Interestingly, CO induces the expression of the cdk inhibitor, p21 ${ }^{\mathrm{WAF} 1 / \mathrm{CIP} 1}$, suggesting that $\mathrm{CO}$ may block cdk2 activity via multiple mechanisms (Duckers et al., 2001). A functional association between $\mathrm{HO}-1$ and $\mathrm{p} 21^{\text {WAF1/CIP1 }}$ in growth regulation is supported by the finding that the antiproliferative action of $\mathrm{HO}-1$ is significantly reduced in VSMCs obtained from p21 ${ }^{\text {WAF1/CIP1 }}$ null mice (Duckers et al., 2001). Moreover, VSMCs obtained from HO1-deficient animals that exhibit excessive proliferation have a corresponding reduction in p21 WAF1/CIP1 levels compared to wild type mice (Duckers et al., 2001). In our study, we found that curcumin, but not tetrahydrocurcumin, increased $\mathrm{p} 21^{\mathrm{WAF} 1 / \mathrm{CIP} 1}$ expression in a HO-1-dependent manner (Figure 4B and 5B), suggesting that the antiproliferative effect of curcumin is mediated, at least in part, via HO-1 expression.
Of importance in our study is the finding that $\mathrm{HO}-1$ expression by curcumin was not restricted to rat VSMCs but also occurred in HASMCs. Similar to our results obtained in rat VSMCs, curcumin-induced HO-1 expression led to p21 WAF1/CIP1 expression and growth inhibition in human smooth muscle cells (Figure 6), as well. These findings may, in part, explain the therapeutic benefits of curcumin for atherosclerosis or restenosis. It should be noted that the anti-restenosis of curcumin was confirmed by a previous in vivo evaluation using pig coronary artery stent model (Nguyen et al., 2004).

Although we have shown that $\mathrm{HO}-1$ expression by curcumin was involved in inhibition of VSMC proliferation, we do not exclude the possibility that curcumin may also induce the expression of other antiproliferative enzyme(s) and that the observed antiproliferative activity of curcumin may be achieved via the concerted actions of the multiple pathways that may be activated and/or inactivated by this phytochemical. In fact, curcumin has been demonstrated to inactivate NF-KB (Dorai and Aggarwal, 2004), AP-1 (Park et al., 1999), extracellular signalregulated kinase (Masamune et al., 2006) and PKC (Gopalakrishna and Gundimeda, 2002), all of which are involved in the regulation of VSMC proliferation. In other words, the multifarious effects of curcumin may help explain why inhibition of VSMC proliferation by curcumin was partially mediated via its $\mathrm{HO}-1$ expression.

In summary, our findings suggest that curcumin at non-cytotoxic doses is capable of inducing both Nrf2dependent $\mathrm{HO}-1$ expression and growth inhibition in rat VSMCs. Neither HO-1 expression nor antiproliferative activity was observed when rat VSMCs were treated with tetrahydrocurcumin, indicating that the conjugated double bonds of the central sevencarbon chain of curcumin may play an important role in its biological activity. In addition, we provided evidence showing that the antiproliferative effect of curcumin is considerably linked to its ability to induce $\mathrm{HO}-1$ expression in rat and human smooth muscle cells. Therefore, curcumin as a vascular $\mathrm{HO}-1$ inducer would be considered as a promising pharmacological agent in the development of therapeutic approaches for the prevention or treatment of vascular obstructive diseases associated with excessive VSMC proliferation.

\section{Acknowledgment}

This work was supported by the Vascular System Research Center grant from the Korea Science and Engineering foundation. 


\section{References}

Andreadi CK, Howells LM, Atherfold PA, Manson MM. Involvement of Nrf2, p38, B-Raf, and nuclear factor-kappaB, but not phosphatidylinositol 3-kinase, in induction of hemeoxygenase- 1 by dietary polyphenols. Mol Pharmacol 2006; 69:1033-40

Balogun E, Hoque M, Gong P, Killeen E, Green CJ, Foresti $\mathrm{R}$, Alam J, Motterlini R. Curcumin activates the haem oxygenase-1 gene via regulation of Nrf2 and the antioxidantresponsive element. Biochem J 2003;371:887-95

Banning A, Deubel S, Kluth D, Zhou Z, Brigelius-Flohe R. The GI-GPx gene is a target for Nrf2. Mol Cell Biol 2005; 25:4914-23

Braun-Dullaeus RC, Mann MJ, Dzau VJ. Cell cycle progression: new therapeutic target for vascular proliferative disease. Circulation 1998;98:82-9

Chainani-Wu N. Safety and anti-inflammatory activity of curcumin: a component of tumeric (Curcuma longa). J Altern Complement Med 2003;9:161-8

Chen HW, Huang HC. Effect of curcumin on cell cycle progression and apoptosis in vascular smooth muscle cells. $\mathrm{Br}$ J Pharmacol 1998;124:1029-40

Dorai T, Aggarwal BB. Role of chemopreventive agents in cancer therapy. Cancer Lett 2004;215:129-40

Duckers HJ, Boehm M, True AL, Yet SF, San H, Park JL, Clinton Webb R, Lee ME, Nabel GJ, Nabel EG. Heme oxygenase-1 protects against vascular constriction and proliferation. Nat Med 2001;7:693-8

Durante W. Heme oxygenase-1 in growth control and its clinical application to vascular disease. J Cell Physiol 2003; 195:373-82

el-Deiry WS, Tokino T, Velculescu VE, Levy DB, Parsons R, Trent JM, Lin D, Mercer WE, Kinzler KW, Vogelstein B. WAF1, a potential mediator of p53 tumor suppression. Cell 1993;75:817-25

Gopalakrishna R, Gundimeda U. Antioxidant regulation of protein kinase C in cancer prevention. J Nutr 2002;132: S3819-23

Huang MT, Ma W, Lu YP, Chang RL, Fisher C, Manchand PS, Newmark HL, Conney AH. Effects of curcumin, demethoxycurcumin, bisdemethoxycurcumin and tetrahydrocurcumin on 12-O-tetradecanoylphorbol-13-acetate-induced tumor promotion. Carcinogenesis 1995;16:2493-7

Ireson C, Orr S, Jones DJ, Verschoyle R, Lim CK, Luo JL, Howells L, Plummer S, Jukes R, Williams M, Steward WP, Gescher A. Characterization of metabolites of the chemopreventive agent curcumin in human and rat hepatocytes and in the rat in vivo, and evaluation of their ability to inhibit phorbol ester-induced prostaglandin E2 production. Cancer Res 2001;61:1058-64

Jeong GS, Oh GS, Pae HO, Jeong SO, Kim YC, Shin MK, Seo BY, Han SY, Lee HS, Jeong JG, Koh JS, Chung HT. Comparative effects of curcuminoids on endothelial heme oxygenase- 1 expression: ortho-methoxy groups are essential to enhance heme oxygenase activity and protection. Exp
Mol Med 2006;38:393-400

Juan SH, Lee TS, Tseng KW, Liou JY, Shyue SK, Wu KK, Chau LY. Adenovirus-mediated heme oxygenase-1 gene transfer inhibits the development of atherosclerosis in apolipoprotein E-deficient mice. Circulation 2001;104:1519-25

Kim TJ, Zhang YH, Kim Y, Lee CK, Lee MK, Hong JT, Yun YP. Effects of apigenin on the serum- and platelet derived growth factor-BB-induced proliferation of rat aortic vascular smooth muscle cells. Planta Med 2002;68:605-9

Lee BS, Heo J, Kim YM, Shim SM, Pae HO, Kim YM, Chung HT. Carbon monoxide mediates heme oxygenase 1 induction via Nrf2 activation in hepatoma cells. Biochem Biophys Res Commun 2006;343:965-72

Maheshwari RK, Singh AK, Gaddipati J, Srimal RC. Multiple biological activities of curcumin: a short review. Life Sci 2006;78:2081-7

Masamune A, Suzuki N, Kikuta K, Satoh M, Satoh K, Shimosegawa T. Curcumin blocks activation of pancreatic stellate cells. J Cell Biochem 2006;97:1080-93

Nguyen KT, Shaikh N, Shukla KP, Su SH, Eberhart RC, Tang L. Molecular responses of vascular smooth muscle cells and phagocytes to curcumin-eluting bioresorbable stent materials. Biomaterials 2004;25:5333-46

Notoya M, Nishimura H, Woo JT, Nagai K, Ishihara $\mathrm{Y}$, Hagiwara $\mathrm{H}$. Curcumin inhibits the proliferation and mineralization of cultured osteoblasts. Eur J Pharmacol 2006;534: $55-62$

Pari L, Murugan P. Protective role of tetrahydrocurcumin against erythromycin estolate-induced hepatotoxicity. Pharmacol Res 2004;49:481-6

Park JM, Adam RM, Peters CA, Guthrie PD, Sun Z, Klagsbrun $M$, Freeman MR. AP-1 mediates stretch-induced expression of HB-EGF in bladder smooth muscle cells. Am J Physiol 1999;277:C294-301

Peyton KJ, Reyna SV, Chapman GB, Ensenat D, Liu XM, Wang $\mathrm{H}$, Schafer Al, Durante W. Heme oxygenase-1-derived carbon monoxide is an autocrine inhibitor of vascular smooth muscle cell growth. Blood 2002;99:4443-8

Sata M. Role of circulating vascular progenitors in angiogenesis, vascular healing, and pulmonary hypertension: lessons from animal models. Arterioscler Thromb Vasc Biol 2006;26:1008-14

Scapagnini G, Foresti R, Calabrese V, Giuffrida Stella AM, Green CJ, Motterlini R. Caffeic acid phenethyl ester and curcumin: a novel class of heme oxygenase- 1 inducers. Mol Pharmacol 2002;61:554-61

Srisook K, Kim C, Cha YN. Molecular mechanisms involved in enhancing $\mathrm{HO}-1$ expression: de-repression by heme and activation by Nrf2, the "one-two" punch. Antioxid Redox Signal 2005;7:1674-87

Sugiyama Y, Kawakishi S, Osawa T. Involvement of the beta-diketone moiety in the antioxidative mechanism of tetrahydrocurcumin. Biochem Pharmacol 1996;52:519-25

Surh YJ. Anti-tumor promoting potential of selected spice ingredients with antioxidative and anti-inflammatory activities: 
a short review. Food Chem Toxicol 2002;40:1091-7

Surh YJ, Kundu JK, Na HK, Lee JS. Redox-sensitive transcription factors as prime targets for chemoprevention with anti-inflammatory and antioxidative phytochemicals. J Nutr 2005;135:2993S-3001S

Uehara SI, Yasuda I, Akiyama K, Morita H, Takeya K, Itokawa $\mathrm{H}$. Diarylheptanoids from the rhizomes of Curcuma xanthorrhiza and Alpina officinarum. Chem Pharm Bull 1987;35: 3298-304
Yang X, Thomas DP, Zhang X, Culver BW, Alexander BM, Murdoch WJ, Rao MN, Tulis DA, Ren J, Sreejayan N. Curcumin inhibits platelet-derived growth factor-stimulated vascular smooth muscle cell function and injury-induced neointima formation. Arterioscler Thromb Vasc Biol 2006;26: 85-90

Yet SF, Layne MD, Liu X, Chen YH, Ith B, Sibinga NE, Perrella MA. Absence of heme oxygenase-1 exacerbates atherosclerotic lesion formation and vascular remodeling. FASEB J 2003;17:1759-61 